Check for updates

Cite this: RSC Adv., 2017, 7, 55148

Received 10th September 2017 Accepted 23rd November 2017

DOI: $10.1039 / c 7 r a 10066 c$

rsc.li/rsc-advances

\section{Revealing the dependence of the physiochemical and mechanical properties of cement composites on graphene oxide concentration $\uparrow$}

\author{
Aliakbar Gholampour, (D) a Meisam Valizadeh Kiamahalleh, (D) bc Diana N. H. Tran, (D) bd \\ Togay Ozbakkaloglu (DD *a and Dusan Losic (D)*bd
}

\begin{abstract}
This paper presents a comprehensive study to evaluate the influence of graphene oxide (GO) concentration on the physiochemical and mechanical properties of cement mortar composites. Scanning electron micrographs (SEM), energy-dispersive $X$-ray spectroscopy (EDX), X-ray diffraction (XRD), thermogravimetric analysis (TGA), and Fourier transform infrared spectroscopy (FTIR) characterizations were performed to understand the correlation between physicochemical and observed axial tension and compression properties of $\mathrm{GO}$-cement mortar composites. The results show considerable concentration dependence, with the optimum concentration of $0.1 \% \mathrm{GO}$ that increases the tensile and compressive strength of the composite by $37.5 \%$ and $77.7 \%$, respectively. These results are explained by the stronger bonding of calcium silicate hydrate $(\mathrm{C}-\mathrm{S}-\mathrm{H})$ components in the cement matrix in the presence of $\mathrm{GO}$ sheets and the dependence of their dispersions and possible aggregation.
\end{abstract}

\section{Introduction}

Cementitious materials are the most widely used construction materials throughout the world. Although this type of material has relatively good compressive strength, brittleness, very low tensile strength and strain, and low flexural strength are their weaknesses. ${ }^{1,2}$ Many researchers have tried to improve the mechanical properties of cementitious materials using different types of fibers and additives. ${ }^{3,4}$ Recently, the use of nanoparticles in cementitious materials to improve their mechanical properties by controlling nanoscale crack formation has received widespread attention.

A large number of studies conducted to date have shown that the use of nanoparticles in cementitious materials results in the delay of nanoscale cracks (at the initial stage of loading) in the material before generation of microscale cracks. ${ }^{3,5-8}$ As was reported by Chang et al. ${ }^{7}$ and Madani et al., ${ }^{8}$ a high specific surface area of nanoparticles (e.g. nanosilica and nanoclay) could result in the accelerated transformation of $\mathrm{C}-\mathrm{S}-\mathrm{H}$ surrounding the

${ }^{a}$ School of Civil, Environmental and Mining Engineering, The University of Adelaide, South Australia, 5005, Australia. E-mail: togay.ozbakkaloglu@adelaide.edu.au

${ }^{b}$ School of Chemical Engineering, The University of Adelaide, South Australia, 5005 Australia.E-mail:dusan.losic@adelaide.edu.au

'Department of Process Engineering, International Maritime College Oman, Falaj Al Qabail, Sohar, 322 Oman

${ }^{d A R C}$ Research Hub for Graphene Enabled Industry Transformation, The University of Adelaide, South Australia, 5005 Australia

$\dagger$ Electronic supplementary information (ESI) available: Experimental details, mechanical testing, SEM data, XRD, and TGA results. See DOI: $10.1039 / \mathrm{c} 7 \mathrm{ra} 10066 \mathrm{c}$ cement particles to the stable form through fast pozzolanic activity. This produces additional $\mathrm{C}-\mathrm{S}-\mathrm{H}$ gel, which improves internal paste-to-aggregate binding. The development of graphene as a new type of carbon and 2-d materials with a unique 2d structure, e.g. high surface area, good chemical, mechanical, and thermodynamic properties, presented a new opportunity to further improve properties of cementitious materials..$^{9-12}$ Graphene is usually prepared by exfoliating the graphite in water using sonication and with oxidation using strong oxidizing agents. Graphite oxide is separated into several single layers, as graphene oxide (GO), which is easily dispersible in water. Another form of graphene is reduced graphene oxide (rGO) prepared by reducing oxygen groups of pristine graphene, which is obtained directly from graphite. Graphene has an intrinsic strength and Young's modulus of up to $130 \mathrm{GPa}$ and $1 \mathrm{TPa}$, respectively. ${ }^{13,14}$ The surface area of the GO layer is theoretically $2600 \mathrm{~m}^{2} \mathrm{~g}^{-1}$, which is higher than those of carbon nanotube and nanosilica (i.e. 1000 and $300 \mathrm{~m}^{2} \mathrm{~g}^{-1}$, respectively). ${ }^{15}$

In recent years, several studies have proposed the significant potential of GO for enhancing mechanical properties of cementitious materials and designing new composites for specific applications. ${ }^{5,6,10,16-21}$ These studies indicated that GO can be dispersed in the cement matrix more homogeneously than graphene and graphite. The microstructure and mechanical properties of the GO-cement mortar have been studied by Lv et al. ${ }^{5}$ and the results showed that the inclusion of GO in the cement mortar results in enhancements in its tensile, compressive, and flexural strengths through formation of the flower-like hydration crystals. Alkhateb et al. ${ }^{16}$ showed that $0.5 \%$ addition of functionalized graphene nano-platelets in the 
cement paste resulted in a $23 \%$ increase in the elastic modulus. Fakhim et al. ${ }^{17}$ reported that the tensile strength of the cement mortar increased by $48 \%$ after the addition of the optimum amount of $1.5 \%$ GO in the composite. Sharma and Kothiyal ${ }^{18}$ found that inclusion of GO sheets with an average size of $900 \mathrm{~nm}$ at a rate of $1 \%$ results in $63 \%$ increase in the compressive strength of cement mortar composites. Slightly different results are reported by Pan et al. ${ }^{6}$ showing that the addition of $0.05 \% \mathrm{GO}$ improves the compressive strength and flexural strength of the GO-cement paste by $33 \%$ and $58 \%$, respectively. Gong et al. ${ }^{19}$ found that the degree of hydration of the cement paste is enhanced by addition of GO amount. They also reported that $0.03 \% \mathrm{GO}$ in the cement composite exhibits $13.5 \%$ lower porosity than the normal cement paste. The addition of GO is confirmed to lower fluidity and improved compressive and flexural strengths for the GO-cement mortar composite in comparison with the conventional cement mortar. ${ }^{20} \mathrm{Lu}$ et $a .^{21}$ investigated the effect of the GO on the mechanical behavior of strain hardening cementitious composites, showing that addition of $0.08 \%$ GO by weight results in $24.8 \%, 37.7 \%, 80.6 \%$, and $105 \%$ increases in the compressive strength, tensile strength, flexural strength, and flexural toughness of the cement mortar composite, respectively. The electrical behavior of the GO-cement paste was also investigated by Singh et al. ${ }^{10}$ showing that the addition of GO with an appropriate amount of ferrofluid results in an increase in the electrical conductivity of the cement paste. As evident from the results of the existing studies, improved mechanical and electrical properties along with the accessible source and highly dispersible properties in water, makes GO a promising material in the preparation of high performance cement mortar composites. ${ }^{6}$

However, although significant progress has been made in previous studies, there is considerable inconsistency in these reports showing different effects of GO on the mechanical properties of composite due to the use of different GO materials and preparation conditions, neither properly characterized. These studies were mainly focused on conducting mechanical tests to show the effect of GO on the mechanical properties of composite without presenting or exploring how properties of used GO materials including the concentration, size, number of layers, defects, and density of oxygen groups could influence these properties. As cementitious materials are complex mixtures involving many components and interactions, the study of the influence of the GO parameters on the molecular bonds, crystalline phases, and hydration degree of the composites is essential to understand and explain the observed impact on mechanical properties. The study of the effect of these GO parameters on the mechanical properties of cement mortar composites is currently missing and it is highly important to understand the mechanisms and fundamental aspects behind the improvements observed in the mechanical properties. Our research team is exploring the parameters of GO including concentration, size, chemistry, and surface modifications in order to improve existing knowledge and better understanding their influence at molecular-, nano-, and micro-scale on mechanical properties of cementitious materials.
In this paper, we present the first in series of studies, with the aim of investigating the influence of GO contents on the physiochemical and mechanical properties of cement mortar composites. To find these correlations, GO-cement mortar composites were prepared using a broad range of GO dosages (i.e. $0-0.5 \%$ by weight of cement) and their physical, structural, chemical, and mechanical properties were comprehensively characterized using scanning electron micrographs (SEM), energy-dispersive X-ray spectroscopy (EDX), X-ray diffraction (XRD), thermogravimetric analysis (TGA), Fourier transform infrared spectroscopy (FTIR), and axial compression and tension tests. The results were used to find the optimal GO concentration that provides the best mechanical performance and to help us to gain better understanding of the mechanisms behind the improvements. Promising results from this study indicate that properties of cement mortar composites can be significantly enhanced by GO and potentially tailored in combination with other additives for specific applications.

\section{Experimental section}

\subsection{Materials}

2.1.1 Preparation of GO. GO was produced from the oxidation of natural graphite using the improved Hummer's method. ${ }^{22}$ A 9:1 mixture of concentrated sulphuric acid and phosphoric acid $(120: 13 \mathrm{ml})$ was cooled overnight to $4{ }^{\circ} \mathrm{C}$. The cooled acid mixture was slowly added to the graphite powder $(1$ $\mathrm{g}$ ) and potassium permanganate $(6 \mathrm{~g})$ during stirring at room temperature. Then, the mixture was heated to $50^{\circ} \mathrm{C}$ for about 12 hours to form a thick paste. After the completion of the reaction, the paste was cooled down to room temperature and quickly poured onto the ice cubes $(150 \mathrm{ml})$ with $30 \%$ hydrogen peroxide $(1 \mathrm{ml})$ for an hour. The mixture was then washed and filtered with distilled water and hydrochloric acid (32\%), followed by repeated washing with ethanol and eventually with Milli-Q water. For each wash, the obtained brown dispersion was centrifuged at $4400 \mathrm{rpm}$ for two hours to remove residual salts and any un-exfoliated graphite oxide. The obtained GO was vacuum dried overnight at room temperature. Fig. S1 (see ESI $\uparrow$ ) shows the graphite powder and final GO solution.

Graphite flakes were obtained from Valence Industries Ltd. Australia. Other chemicals, including $98 \%$ sulfuric acid $\left(\mathrm{H}_{2} \mathrm{SO}_{4}\right.$, Sigma-Aldrich), $85 \%$ phosphoric acid $\left(\mathrm{H}_{3} \mathrm{PO}_{4}\right.$, Chem-Supply), potassium permanganate $\left(\mathrm{KMnO}_{4}\right.$, Sigma-Aldrich $), \quad 30 \%$ hydrogen peroxide $\left(\mathrm{H}_{2} \mathrm{O}_{2}\right.$, Chem-Supply), $35 \%$ hydrochloric acid ( $\mathrm{HCl}, \mathrm{Merck})$, and ethanol (Chem-Supply) were used. Milli$\mathrm{Q}$ water (Purelab option-Q, $18.2 \mathrm{M} \Omega \mathrm{cm}$ at $25^{\circ} \mathrm{C}$ and a pH of 5.6) was used in all aqueous solutions.

2.1.2 Preparation of cement mortar. Ordinary Portland cement and graded river sand of $2 \mathrm{~mm}$ maximum size were used in the preparation of the cement mortars. Tables S1 and S2 (see ESI $\dagger$ ) show the particle size distribution of the sand and chemical composition of the Portland cement used in this study, respectively. GO was added to the mortar mixes at eight different contents of $0 \%$ (as a control sample), $0.01 \%, 0.03 \%$, $0.05 \%, 0.07 \%, 0.1 \%, 0.3 \%$, and $0.5 \%$ by weight of cement for the preparation of the GO-cement mortar composites. These 
GO concentrations were determined based on a preliminary study and careful review of the literature to establish an optimum amount of GO for improving the tensile and compressive strength of cement mortar composites., ${ }^{5,6,17,20,21}$ All of the mixes had a water to cement ratio (w/c) of 0.485 . The mix proportions of these eight mixes are shown in Table S3 (see ESI $\dagger$ ). Three nominally identical specimens were tested for each unique specimen configuration in direct tension and compression tests. Polycarboxylic ether polymer-based superplasticizer with the properties shown in Table S4 (see ESI $\dagger$ ) was used in all mixes to increase the workability and ensure the uniform dispersion of GO particles in the composite. Flowability test was conducted on the fresh mortar mixes to investigate their workability according to the ASTM standard C1437. ${ }^{23}$ Table S5 (see ESI $\dagger$ ) shows the results of flowability tests. For the direct tension tests, typical dog-bone shaped samples with a test region width and depth of $25 \pm 0.5 \mathrm{~mm}$ were used in accordance with the ASTM standard C307-03. ${ }^{24} 50 \mathrm{~mm}$ cube samples were used for the compression tests according to the ASTM standard C109/ C109M-07. ${ }^{25}$

In order to improve the dispersion of GO in the mortar mixture, the following procedure was adopted: firstly, cement and sand were mixed together at a low speed of $40 \mathrm{rpm}$ for 2 min. Then, superplasticizer was added to the GO solution and the mixture was sonicated for $10 \mathrm{~min}$. Finally, GO solution was gradually added to the mix and the materials were mixed for 5 min before the mixtures were poured into the moulds. Once the specimens were demolded, they were cured in the fog room at a constant temperature of $23 \pm 2{ }^{\circ} \mathrm{C}$ until the test days. Fig. S2 (see ESI $\dagger$ ) shows the samples used in the direct tension and compression tests.

\subsection{Characterizations}

2.2.1 Transmission electron microscopy (TEM). The morphology of GO particles was characterized with a transmission electron microscope (Phillips TEM CM200, FEI, USA) operating at an accelerating voltage of $160 \mathrm{kV}$. The sample was prepared by sonicating GO in water for $60 \mathrm{~min}$ and then drop casting the dispersion on a Lacey copper grid for analysis.

2.2.2 Scanning electron microscopy (SEM). The dispersion and bonding properties between the GO sheets at the surface of the cement mortar were investigated by High Resolution Field Emission Scanning Electron Microscope (FEI Quanta 450). The SEM analysis was conducted after the 28 days mechanical tests and on the polished fresh cut surface of the specimen, which was cut with dimensions of approximately $8 \times 4 \times 3 \mathrm{~mm}$. The specimens were then coated by a $10 \mathrm{~nm}$-thick platinum layer to enhance the conductivity in the SEM analysis.

2.2.3 Atomic force microscopy (AFM). The thickness of GO was characterized with a Ntegra Solaris atomic force microscopy (NT-MDT, Russia) in semi-contact (tapping) mode at room temperature using a NSG10 probe made of silicon nitride with a $10 \mathrm{~nm}$ tip radius. The sample was prepared by dispersing GO in ethanol, drop casted on a cleaned silicon wafer, then left to dry in air before analysis.
2.2.4 Composition analysis. The composition of the mortar matrix was determined in two ways. Energy Dispersive X-ray (EDX) spectroscopy was conducted on the polished fresh cut surface of specimens using TEAM EDS with SDD detector to determine the constituent elements of the materials, whereas $\mathrm{X}$ ray diffraction (XRD) was performed using X-ray diffractometer (Rigaku MiniFlex 600, Japan), at $40 \mathrm{kV}$ and $15 \mathrm{~mA}$ in the range of $2 \theta=5-80^{\circ}$ with a scanning rate of $10^{\circ} \mathrm{C} \mathrm{min}^{-1}$ and $\mathrm{CuK} \alpha$ radiation $(\lambda=1.540 \AA)$, to determine the crystalline phases of the GO and GO-enriched hydrated cementitious composite materials.

2.2.5 Thermogravimetric analysis (TGA). Thermal decomposition of GO was performed on the composites by a thermal gravimetric analyzer (TGA Q500, USA) under air atmosphere where the sample was heated from room temperature to $1000{ }^{\circ} \mathrm{C}$ at a heating rate of $20{ }^{\circ} \mathrm{C} \mathrm{min}^{-1}$. Also, in order to examine the influence of GO incorporation on the hydration properties of the cement paste, TGA was performed on the samples after 7 and 28 days of curing. Samples were kept in an alumina crucible and a Mettler Toledo TGA testing machine was used for the analysis. In each test, approximately $25-35 \mathrm{mg}$ of composite was heated from room temperature to $1000{ }^{\circ} \mathrm{C}$ under the flow of nitrogen with a heating rate of $10{ }^{\circ} \mathrm{C} \mathrm{min}^{-1}$.

In the TGA, two parameters of evaporable (free) and nonevaporable (bound) water contents are determined. The content of the evaporable water, which is the water on the outer surface of the composite particles, is recorded as a percentage of the weight loss for temperatures that ranged from room temperature to $145^{\circ} \mathrm{C}$. The content of non-evaporable water is determined as the percentage of the weight loss from $145^{\circ} \mathrm{C}$ to $1000{ }^{\circ} \mathrm{C}$, minus the weight loss from $600{ }^{\circ} \mathrm{C}$ and $800{ }^{\circ} \mathrm{C}$, as a result of the $\mathrm{CO}_{2}$ release by the calcite decomposition. ${ }^{19,26-29}$ The non-evaporable water content of GO-cement composite is used to calculate the hydration degree of the sample (i.e. $\alpha \operatorname{TGA}(t))$ using the following equation: ${ }^{26}$

$$
\alpha \operatorname{TGA}(t)(\%)=\left(W_{\mathrm{n}}(t)\right) /\left(M_{\mathrm{c}} \times W_{\mathrm{n}}(\infty)\right) \times 100
$$

where $W_{\mathrm{n}}(\infty)$ is the non-evaporable water mass $\left(\mathrm{g} \mathrm{g}^{-1}\right.$ of cement) at the time $t \rightarrow \infty . t \rightarrow \infty$ corresponds to the time of full hydration of $1 \mathrm{~g}$ of cement, in which $W_{\mathrm{n}}(\infty)$ is estimated as $0.2293 \mathrm{~g}$ from the mineralogical composition of cement. ${ }^{30} W_{\mathrm{n}}(t)$ and $M_{\mathrm{c}}$ are the non-evaporable water mass at the time $(t)$ and the initial anhydrous paste mass of the sample in $g$, respectively.

2.2.6 Fourier transform infrared spectroscopy (FTIR). Vibrational stretching modes of different molecular bonds, including GO oxygen functional groups as well as the formation of $\mathrm{Ca}(\mathrm{OH})_{2}$ and $\mathrm{C}-\mathrm{S}-\mathrm{H}$ in the $\mathrm{GO}$-hydrated cementitious composite materials, were confirmed by Fourier transform infrared spectroscopy (FTIR) analysis using Nicolet 6700 Thermo Fisher. ${ }^{29}$

2.2.7 Raman spectra. Raman measurements were performed on a LabRAM HR Evolution Raman spectrometer (Horiba Scientific, Japan) with a $532 \mathrm{~nm}$ laser scanned from 750 to $3000 \mathrm{~cm}^{-1}$. The parameters were set up as follows: a $50 \times$ 
objective, spot size of 100, 25\% laser power, and $10 \mathrm{~s}$ integration time for 3 accumulations.

2.2.8 Mechanical characterizations of tension and compression performances. To evaluate the mechanical behavior of the mortar samples with different GO contents, prepared specimens were tested under axial tension and compression loadings with displacement control. Fig. S3 (see ESI $\dagger$ ) shows the equipment used in these tests. The ultimate tensile and compressive strengths were averaged from three tests on identical specimens for each mix proportions. The axial compressive strains of the specimens were measured by two linear variable displacement transformers (LVDTs) mounted at the corners of steel loading and supporting plates.

\section{Results and discussion}

\subsection{Physical and chemical characterization of GO-cement mortar composites}

Fig. 1 shows the characterization results of GO sheets used for making cement mortar composites. Fig. 1(a) shows a typical TEM image of GO sheets showing their irregular shape and amorphous nature with a paper-like appearance with an approximate thickness of $1 \mathrm{~nm}$, attributing to be a single layer sheet (see Fig. S1 in ESI $\dagger$ ). The crystal structure of GO was evaluated by XRD showing the characteristic 002 reflection peak at $2 \theta$ (scattering angle $)=11.1^{\circ}(d$-spacing $=0.79 \mathrm{~nm}$, Fig. $1(\mathrm{~b}))$ and TGA (Fig. 1(c)) confirmed the typical decomposition pattern of GO related to its oxygen functional groups..$^{31-34}$

In order to explain the influence of the GO content on the mechanical behavior of the cement mortar composite, SEM, EDX, XRD, TGA, and FTIR tests were performed on the composites with GO dosages of $0 \%$ (as the control sample), $0.03 \%$ (as representative effective low dosage), $0.1 \%$ (as the optimum dosage obtained from mechanical results), and $0.5 \%$ (as the maximum dosage).

Fig. 2 shows the cracking patterns of the prepared cement mortar composites with GO contents of $0 \%, 0.03 \%, 0.1 \%$, and $0.5 \%$ using low magnification SEM images. As shown in Fig. 2, the density of micro-cracks attributed to the poor bonding between the microparticles (sand and cementitious particles) in both cement mortar composites with $0 \%$ and $0.5 \%$ of GO incorporation is higher than those with $0.03 \%$ and $0.1 \%$ GO incorporation. This behavior is attributed to the high
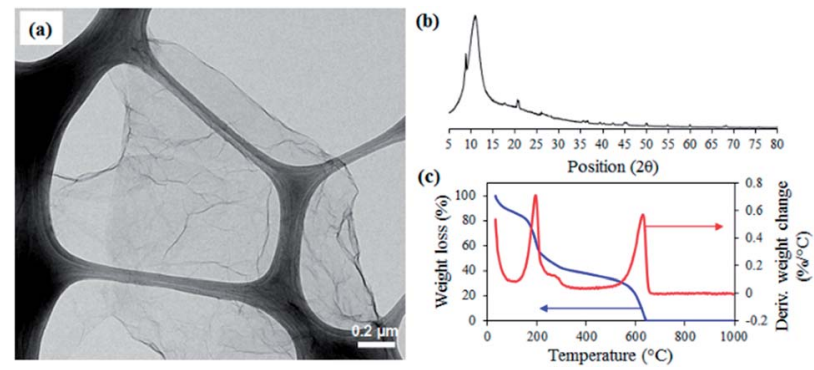

Fig. 1 (a) TEM image, (b) XRD, and (c) TGA plots of GO material exfoliated from graphite and used for composite preparation.
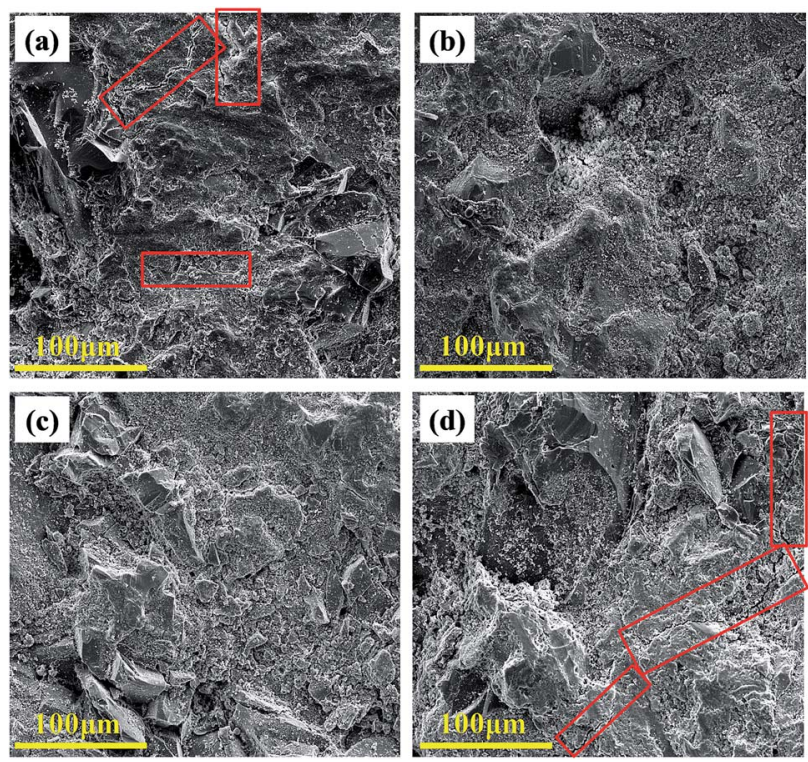

Fig. 2 Low magnification SEM images of the cross-sectional structures of cement mortars with different GO contents (\%): (a) $0 \%$, (b) $0.03 \%$, (c) $0.1 \%$, and (d) $0.5 \%$. Red boxes highlight the micro-cracks on the composite with no GO (a) and high concentration of GO (i.e. $0.5 \%$ ) (d).

dispersibility of GO sheets in the composite at up to an optimum GO concentration, which make them efficient in reinforcing the bridge of the micro-cracks and control the crack propagation from nanoscale to microscale. ${ }^{3,35}$ Fig. S4 (see ESI $\dagger$ ) shows the enlarged cracks in cement mortar composites containing $0 \%$ and $0.5 \%$ GO.

Fig. 3 shows high magnification SEM images at the surface of the samples with GO contents of $0 \%, 0.03 \%, 0.1 \%$, and $0.5 \%$. Fig. S5 (see ESI $\dagger$ ) shows the enlarged SEM images of GO dispersion in cement mortar composites. As can be seen in Fig. 3(a), after hydration the plain mortar consists of pores, which were partially filled with the cement paste, and some gaps, which yet remained between the particles. By increasing the GO content to $0.03 \%$ and $0.1 \%$ (Fig. 3(b) and (c), respectively), the GO sheets were uniformly dispersed between the mortar materials without any aggregation in the cementitious mortar matrix. In these GO contents, the GO sheets were found to be embedded as an individual sheet in the paste that were strongly anchored on the particles and acted as bridges between hydrates and across the composite particles. It can be seen from Fig. $3(\mathrm{~d})$ that, with an increase in the GO content up to $0.5 \%$, GO sheets are re-stacked and re-agglomerated to platelets, which resulted in the poor bond, interparticle interaction, and bridging in the mortar microstructure. This behavior is attributed to the trapping of most of the GO in-plane oxygen groups between the GO layers that prevents them from being able to contribute to the hydration and interaction with the $\mathrm{C}-\mathrm{S}-\mathrm{H}$ bonds. ${ }^{16,36}$ The scheme to visualize the two stages with uniformly dispersed and aggregated GO sheets as a result of different GO concentration is presented in Fig. 3(e) (left and right, respectively). This is the first observation and report of the 

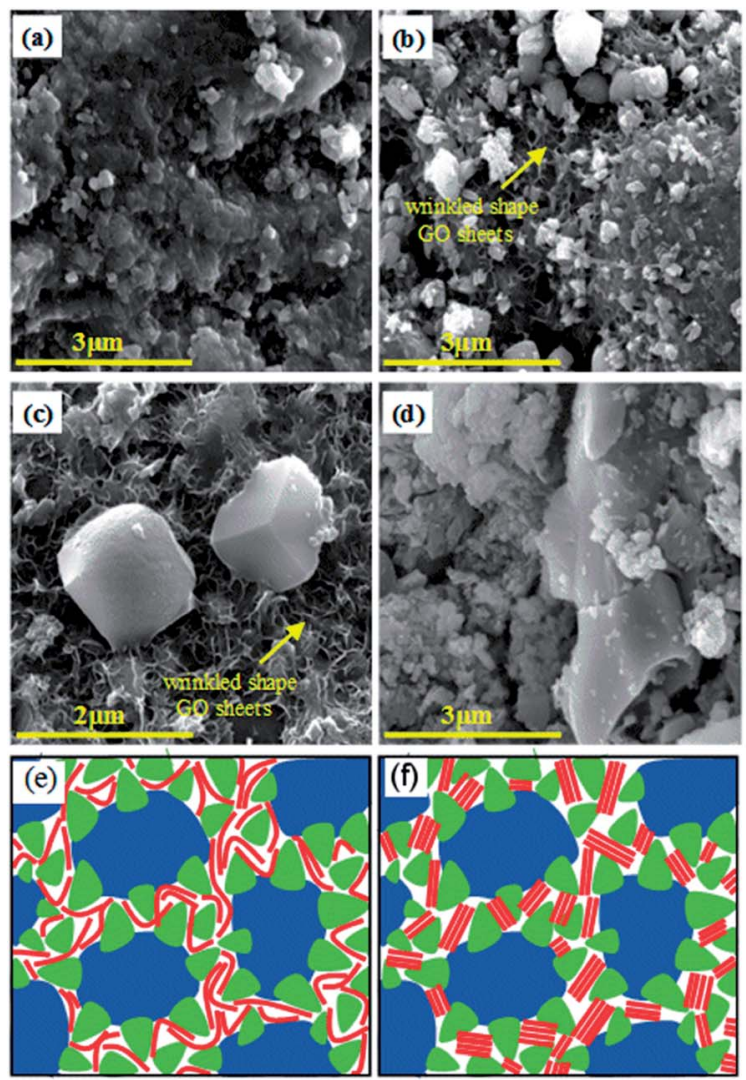

- GO Cement

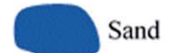

Fig. 3 High magnification SEM micrographs of cement mortars with different GO contents (\%): (a) $0 \%$, (b) $0.03 \%$, (c) $0.1 \%$, and (d) $0.5 \%$. (b and c) show the presence of $\mathrm{GO}$ sheets with good dispersion that are anchored to large cement and sand particles. GO sheets with high concentration in (d) stack and take flake shapes in the matrix. (e and f) show the scheme to visualize uniformly dispersed GO sheets (left) and aggregated multi-layer GO sheets with poor dispersion (right) between cement mortar materials, respectively.

threshold GO concentration in cement composites. Considering that observed aggregation of GO sheets in cement mortar composites is not only dependent on GO concentration but also potentially on other parameters including the size of GO, their charge, condition of their mixing with mortar, and composition of mortar composites, this could explain the large discrepancy in results on the mechanical properties of these composites in previous reports.

Fig. 4 shows the EDX analysis results of prepared cement samples showing the changes of elemental composition using different dosages of GO. As can be seen in the figure, although plain cement mortar does not have any GO, there is a noteworthy amount of carbon in its composite. This is due to the presence of carbon in superplasticiser added as an additive to improve mixing. As can be seen in Fig. 4, the carbon content of the cement mortar composite increased with an increase in the GO concentration.

The influence of the GO concentration on the hydration degree of the GO-cement composites is shown in Fig. 5. The hydration degree values were calculated using eqn (1). Each

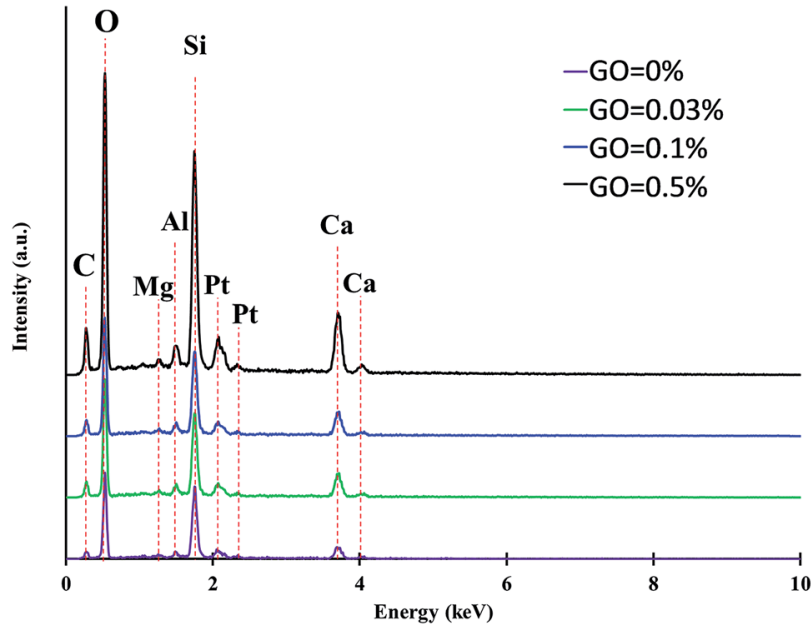

\begin{tabular}{|l|c|c|l|c|c|}
\hline Element & Wt \% & At \% & Element & Wt \% & At \% \\
\hline C K & 5.96 & 10.52 & C K & 7.23 & 12.70 \\
\hline O K & 39.65 & 52.50 & O K & 40.15 & 52.95 \\
\hline MgK & 0.60 & 0.52 & MgK & 0.78 & 0.68 \\
\hline AlK & 1.92 & 1.50 & AlK & 2.16 & 1.69 \\
\hline SiK & 33.45 & 25.23 & SiK & 25.96 & 19.50 \\
\hline CaK & 18.42 & 9.73 & CaK & 23.72 & 12.48 \\
\hline Total & 100 & 100 & Total & 100 & 100 \\
\hline & & & & & \\
\hline Element & Wt \% & At \% & Element & Wt \% & At \% \\
\hline C K & 8.24 & 14.35 & C K & 9.72 & 16.65 \\
\hline O K & 39.74 & 51.99 & O K & 38.92 & 50.05 \\
\hline MgK & 0.65 & 0.56 & MgK & 1.56 & 1.32 \\
\hline AlK & 2.29 & 1.78 & AlK & 2.17 & 1.66 \\
\hline SiK & 25.52 & 19.02 & SiK & 26.79 & 19.63 \\
\hline CaK & 23.56 & 12.30 & CaK & 20.84 & 10.70 \\
\hline Total & 100 & 100 & Total & 100 & 100 \\
\hline
\end{tabular}

Fig. 4 EDX analysis of the GO-cement mortar composite with different GO contents.

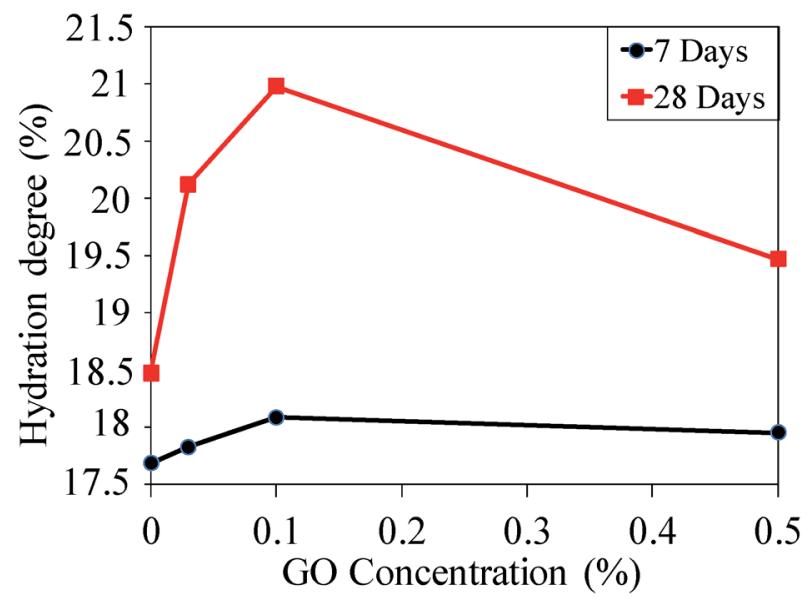

Fig. 5 Hydration degree of the GO-cement composites prepared with different $\mathrm{GO}$ concentrations cured for 7 and 28 days.

term of the equation was derived from the TGA plots provided in Fig. S6 (see ESI†). Fig. 5 shows that the hydration degree of the samples increases with an increase in the curing time from 7 to 28 days regardless of the GO content in the cement paste composite. This observation is in agreement with the previous 
study by Gong et al. ${ }^{19}$ In addition, it is observed that the certain level of GO concentration in the composite plays a significant role in the hydration degree. The results show that the hydration degree increased by $8.2 \%$ and $11.9 \%$ at 28 days compared to the plain composite by increasing the GO dosages to $0.03 \%$ and $0.1 \%$, respectively. Maximum wettability was achieved by $0.1 \%$ GO content, which is proportional to the hydration degree of the composite. This can be attributed to the direct interaction of the GO individual sheets with the cement constituents. By increasing the GO dosage up to $0.5 \%$, the wettability and hydration properties of the cement composite decreased due to the agglomeration of the GO sheets. The stacked GO sheets restricted the penetration of the water molecules into the GO interlayers.

Comparative XRD spectra of Portland cement, sand, and GO-cement mortar mixes are shown in Fig. 6. As can be seen in the figure, the most dominant peaks detected in the XRD patterns are at the scattering angles $(2 \theta)$ of $22^{\circ}$ and $28^{\circ}$ which are indicative from the quartz as this is the only crystalline phase of the sand..$^{37,38}$ It can be seen from the insets (iii) and (iv) in Fig. 6 that after the formation of the tricalcium silicate $\mathrm{C}_{3} \mathrm{~S}$ $\left(\mathrm{Ca}_{3} \mathrm{SiO}_{5}\right)$ and dicalcium silicate $\mathrm{C}_{2} \mathrm{~S}\left(\mathrm{Ca}_{2} \mathrm{SiO}_{4}\right)$, the hydration process continued to create the cement paste containing portlandite $\mathrm{Ca}(\mathrm{OH})_{2}$ and calcium silicate hydrate $(\mathrm{C}-\mathrm{S}-\mathrm{H}) .{ }^{39}$ This hydration process contributes to the enhancement of the strength and volume stability of the cementitious materials. ${ }^{40}$ The XRD peaks shown in inset (i) at the scattering angles of
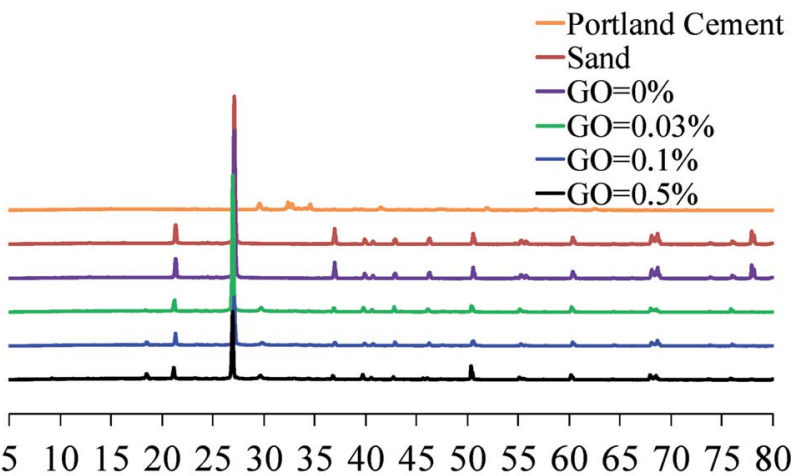
Position $(2 \theta)$ (i)

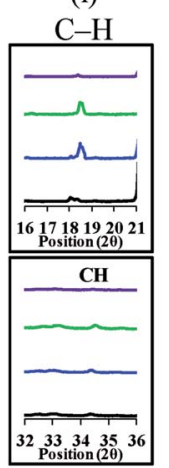

(ii)

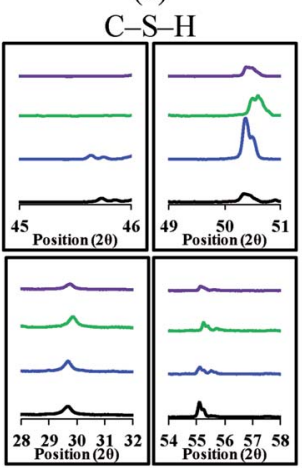

(iii)

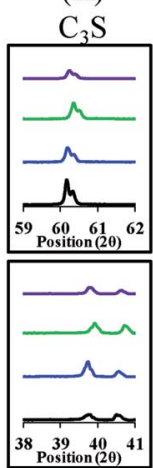

(iv) $\mathrm{C}_{2} \mathrm{~S}$

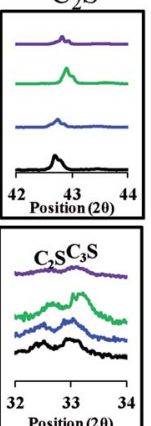

Fig. 6 XRD patterns of Portland cement, sand, and GO-cement composites. about $18^{\circ}$ and $34^{\circ}$ correspond to the formation of $\mathrm{Ca}(\mathrm{OH})_{2} \cdot \cdot^{39,41,42}$ As can be seen in inset (i), the $\mathrm{Ca}(\mathrm{OH})_{2}$ peaks were intensified by an increase in the GO concentration up to $0.1 \%$. A similar trend was also observed for the $\mathrm{C}-\mathrm{S}-\mathrm{H}$ as shown in inset (ii), where the cumulative intensity at $2 \theta$ of $29.6^{\circ}, 45.7^{\circ}, 50.3^{\circ}$, and $55.2^{\circ}$ was the maximum for the cement mortar composite with $0.1 \% \mathrm{GO}$ concentration. This further confirms that increasing the GO content in the cementitious composites enhances the wettability and hydration of the composite, which results in a higher strength. The increased wettability of the composite with GO dosage of up to $0.1 \%$ can be attributed to the increase in the density of the oxygen functional groups (hydrophilic) located on the GO surface. With an increase in GO concentration in the composite beyond a certain level (i.e. $0.1 \%$ ), the highly strong interlayer hydrogen bonds help the GO sheets to stack and agglomerate. Therefore, the GO interlayer distance drops to $6 \AA$ and the water molecules are hardly able to diffuse into the GO layers. $^{43}$

In order to investigate the influence of the GO incorporation into the hydration of the cement mortar mix, the FTIR analysis was conducted on the specimens and composite ingredients (i.e. GO, cement, and sand). Fig. S7† shows the FTIR analysis results in transmittance mode. Major peaks for the GO are: the O-H stretching vibrations from $3000 \mathrm{~cm}^{-1}$ to $3500 \mathrm{~cm}^{-1}$ as a broad peak and at $1413 \mathrm{~cm}^{-1}$ as a narrow peak; the stretching vibrations of $\mathrm{C}=\mathrm{O}$ in carbonyl and carboxyl group at $1720 \mathrm{~cm}^{-1}$; the in-plane $\mathrm{C}=\mathrm{C}$ ( $\mathrm{sp}^{2}$ carbon) skeletal stretching vibrations at $1616 \mathrm{~cm}^{-1}$; and the stretching peaks at $1225 \mathrm{~cm}^{-1}$ and $1050 \mathrm{~cm}^{-1}$ for the $\mathrm{C}-\mathrm{O}$ (epoxy and alkoxy groups). These peaks are in agreement with those reported in the previous studies. ${ }^{31,32}$ The FTIR spectra of the sand with its major stretching vibrations peaks of $\nu_{\text {as }}(\mathrm{Si}-\mathrm{O}-\mathrm{Si}), \nu_{\mathrm{s}}(\mathrm{Si}-\mathrm{O}-\mathrm{Si})$, and $(\mathrm{Si}-\mathrm{OH})$ are also consistent with those reported in literature. ${ }^{\mathbf{4 4 , 4 5}}$ For the Portland cement, the major stretching vibration bands are observed at about $875 \mathrm{~cm}^{-1}$ and $1410 \mathrm{~cm}^{-1}$, which is attributed to the presence of $\mathrm{CO}_{3}$ from $\mathrm{CaCO}_{3}{ }^{46}$ The peaks at the stretching bands of $450 \mathrm{~cm}^{-1}$ and $1080 \mathrm{~cm}^{-1}$ correspond to $\nu_{4}(\mathrm{O}-\mathrm{Si}-\mathrm{O})$ and $\nu_{3}(\mathrm{Si}-\mathrm{O})$ stretching vibration, respectively, in $\mathrm{SiO}_{4}$ tetrahedron. ${ }^{6}$ The minor vibration band at about $3640 \mathrm{~cm}^{-1}$ corresponds to the $\mathrm{O}-\mathrm{H}$ stretching band from $\mathrm{Ca}(\mathrm{OH})_{2}$. This peak exists in all cement mortar composites spectra. These observations are also in agreement with the XRD analysis results in Fig. 6, which shows the formation of $\mathrm{Ca}(\mathrm{OH})_{2}$ with the scattering angle of $18^{\circ}$.

As can be seen in Fig. 7, the most significant difference between the cement mortar composites, GO, cement, and sand particles is the creation of a new broad band at about $980 \mathrm{~cm}^{-1}$. This change can be attributed to the formation of the $\mathrm{C}-\mathrm{S}-\mathrm{H}$ phases in the Portland cement as well as the anhydrous phase and/or $(\mathrm{Si}-\mathrm{O})$ absorption bands of $\mathrm{C}_{2} \mathrm{SH}_{2} \cdot{ }^{47}$ With regard to the GO-cement mortar composites, the intensity of the $\mathrm{O}-\mathrm{H}$ stretching vibrations was increased compared to that of the plain cement mortar and the $\mathrm{C}=\mathrm{O}$ stretching band shifted toward the right side (i.e. lower wavenumber). In other words, the addition of the GO into the plain cement mortar lets the $-\mathrm{OH}$ and $-\mathrm{COOH}$ groups interact preferentially with $\mathrm{C}_{3} \mathrm{~S}, \mathrm{C}_{2} \mathrm{~S}$, and tricalcium aluminate $\mathrm{C}_{3} \mathrm{~A}\left(\mathrm{Ca}_{3} \mathrm{Al}_{2} \mathrm{O}_{6}\right)$, which results in the growth of the hydration products of $\mathrm{C}-\mathrm{S}-\mathrm{H}{ }^{5}$ 


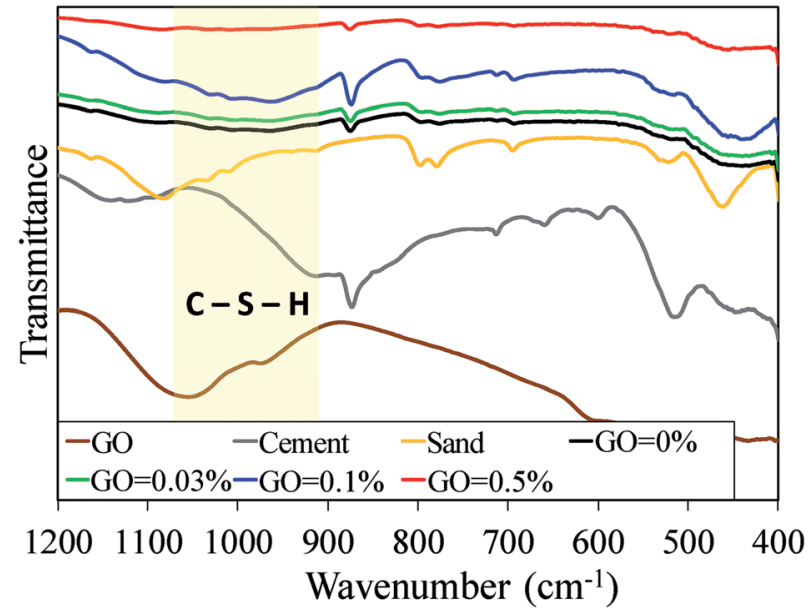

Fig. 7 Creation of a new broad band in comparative FTIR spectra of GO-cement mortar composites.

As can be seen from Fig. $\mathrm{S} 7, \uparrow$ the $\mathrm{O}-\mathrm{H}$ stretching broad band at $3400 \mathrm{~cm}^{-1}$ and $\mathrm{C}=\mathrm{O}$ band at $1640 \mathrm{~cm}^{-1}$ intensified with an increase in GO content up to $0.1 \%$. This is not only due to the increase in the number of the oxygen groups interacting through the hydrogen bonds to the calcium silicate hydrate, ${ }^{21}$ but also because of the increase in the intercalated water in the well-dispersed GO in the cement mortar matrix. ${ }^{48}$ It is also notable that the oxygen functional groups of the graphitic carbon allow the cement $\mathrm{C}-\mathrm{S}-\mathrm{H}$ components to be deposited on the graphitic surface and form a strong interaction between them. This can result in the improvement of the mechanical strength by enhancing the load transfer efficiency as well as the bond strength between the two surfaces (i.e. $\mathrm{C}-\mathrm{S}-\mathrm{H}$ and graphitic surfaces). The highest intensity of the $\mathrm{O}-\mathrm{H}$ and $\mathrm{C}=\mathrm{O}$ stretching peaks was found in the cement mortar mix with GO dosage of $0.1 \%$. This also confirms the highest accessibility of the water to both the GO oxygen functional groups and the cement $\mathrm{C}-\mathrm{S}-\mathrm{H}$ phase, which resulted in the highest hydration degree for the mortar matrix and thus notable enhancements in the mechanical properties of GO-cement mortar composites.

In the case of the cement mortar composite with GO dosage of $0.5 \%$, it can be seen from the Fig. $\mathrm{S} 7 \dagger$ that the $\mathrm{O}-\mathrm{H}$ and $\mathrm{C}=\mathrm{O}$ stretching bands disappear. This behavior is attributed to the diminution of GO and $\mathrm{C}-\mathrm{S}-\mathrm{H}$ intermolecular interaction. This result confirms the SEM observation that the in-plane oxygen functional groups of the highly concentrated GO sheets have the least exposure to the water molecules and almost no contact with the $\mathrm{C}-\mathrm{S}-\mathrm{H}$ phase. This further indicates the poor interaction between the GO oxygen functional groups and the $\mathrm{C}-\mathrm{S}-\mathrm{H}$ phase of the cement in the mortar matrix.

\subsection{Mechanical behavior of GO-cement mortar composites}

The results of the tension and compression tests are summarized in Fig. 8 and 9, respectively, to investigate the influence of the GO concentration on the mechanical behavior of the cement mortar composite. It can be seen from Fig. 8 that the inclusion of GO in the cement mortar results in an increase in the 7 and

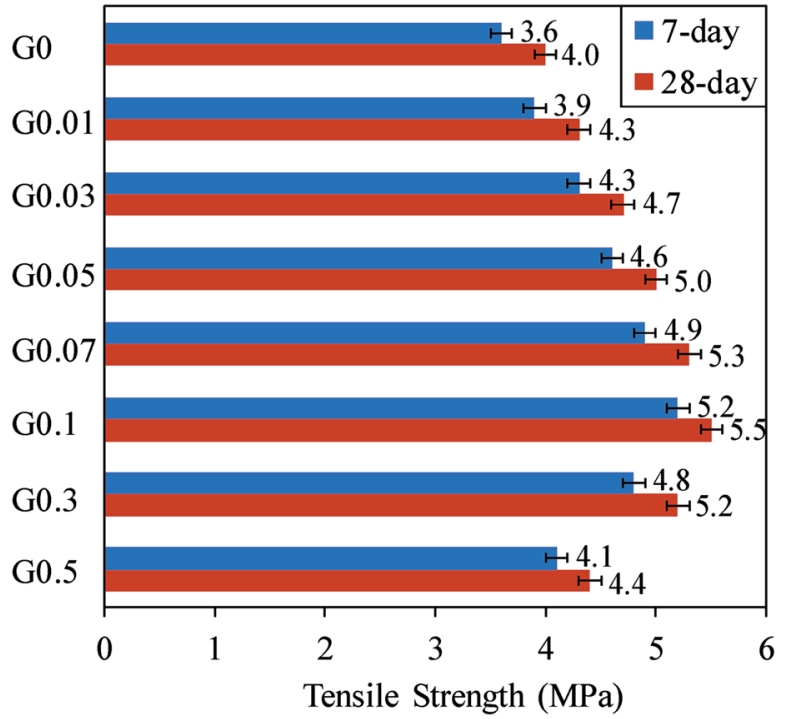

Fig. 8 Variation of 7 and 28 days tensile strength of GO-cement mortar with different $\mathrm{GO}$ contents $(0-0.5 \%)$. Number after letter $\mathrm{G}$ shows GO content of the mix in percentage.

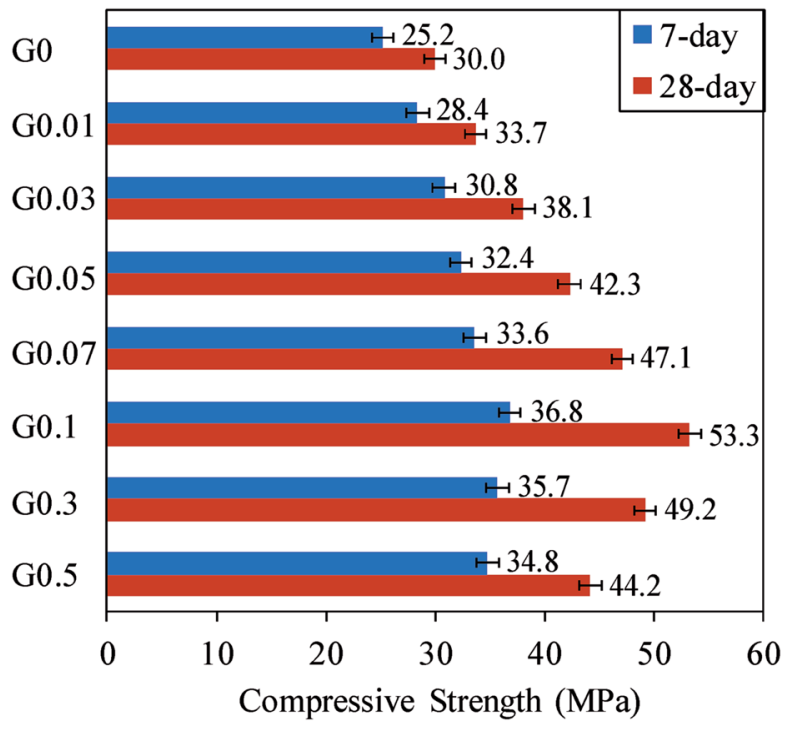

Fig. 9 Variation of 7 and 28 days compressive strength of $\mathrm{GO}$-cement mortar with different $\mathrm{GO}$ contents $(0-0.5 \%)$.

28 days tensile strength of the composite. The tensile strength of the specimens also steadily increases with the addition of GO up to $0.1 \%$, then beyond this level the strength starts to decrease. The strength enhancement of the mix containing $0.1 \%$ GO reached $44.4 \%$ at 7 days and $37.5 \%$ at 28 days. This observation is consistent with previous studies by Lv et al. ${ }^{5}$ and Fakhim et al. ${ }^{17}$ on the GO-cement mortar composite.

The improvement in the tensile strength at the optimum concentration of GO in the cement mortar composites can be attributed to the improved bonding between the cement matrix and GO particles owing to the high dispersibility of GO sheets (as appearing like individual sheets) in the composite at the 
optimum GO concentration (see Fig. 3). High GO dispersion in the composite results in the interaction of cement hydration products (i.e. $\mathrm{C}-\mathrm{S}-\mathrm{H}$ ) with higher surface area GO sheets, leading to the enhanced interfacial load transfer between the GO sheets and cement matrix during the fiber pull out from the matrix. ${ }^{5,6,21}$ However, further increase in the amount of GO results in the GO re-stacking due to van der Waals force, which results in poor dispersion of the GO in the matrix and reduction in the bonding and internal friction within the composite as indicated in scheme in Fig. 3(e). This in turn reduces the strength of the composite. ${ }^{6,21}$

Fig. 9 shows the 7 and 28 days compression test results of different mixes. It can be seen from the figure that the compressive strength of the specimens steadily increased with the GO addition up to a concentration of $0.1 \%$, and the strength decreased with a further increase in the GO content. This trend is consistent with those reported by Cao et al. $^{20}$ and Du and Pang $^{48}$ on the GO-cement mortar composite. The compressive strength enhancement of the mix containing $0.1 \%$ GO reached $46 \%$ at 7 days and $77.7 \%$ at 28 days. It is worth noting that the maximum enhancement seen at the 28 days compressive strength is larger than those in previous studies by Lv et al. ${ }^{5}$ (47.9\%), Pan et al. ${ }^{6}$ (24\%), Cao et al. ${ }^{20}(20.3 \%)$, and Lu et al. ${ }^{21}$ (24.1\%) on the GO-cement mortar composite. Comparison of Fig. 8 and 9 reveals that, for a given mix, compressive strength enhancements seen in GO mixes from 7 to 28 days are higher than those of tensile strength, indicating that the effect of GO on the tensile strength is mostly up to 7 days, whereas the compressive strength enhancement is more progressive and continues beyond the 7 days to 28 days curing age.

The enhancement of the compressive strength is attributed to the good dispersibility of GO sheets in the composite that leads to the better interlocking behavior between the GO and cement mortar and increased crack tip toughness, resulting in the prevention of the crack propagation from nanoscale to microscale. ${ }^{6,18,21}$ However, an increase in the GO content over the optimum amount results in the aggregation of the GO in the matrix that provides poor dispersion and change in the

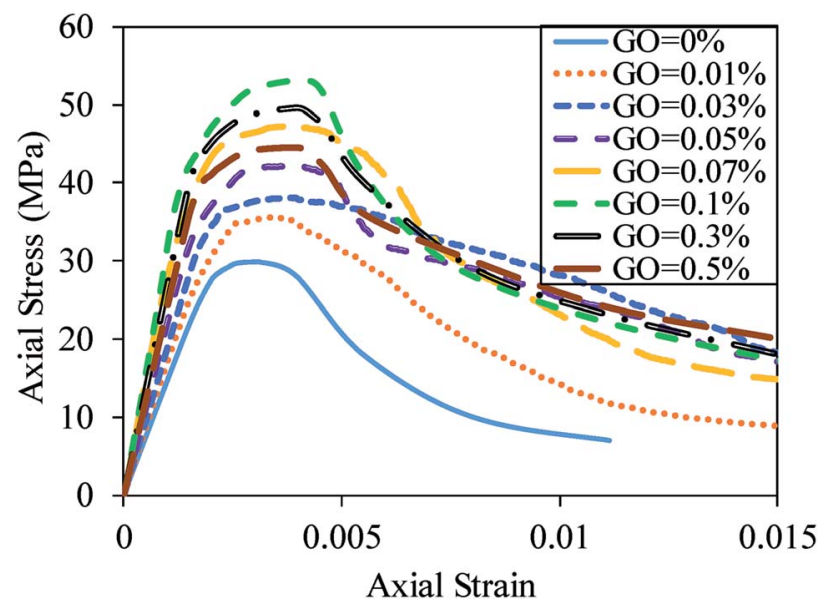

Fig. 10 Variation of 28 days compressive axial stress-axial strain with different GO contents. thickness of the GO to multi layers. ${ }^{\mathbf{1 8 2 1}}$ Multi-layer GO obtains poor interlocking cohesion between GO and the cement mortar, consequently reducing the strength of the composite. $^{21}$

Fig. 10 shows the relationship between the axial compressive stress and strain for cement mortar composites with different GO concentrations at 28 days. The curves indicate that an increase in the GO content up to $0.1 \%$ results in an increase in the compressive strength of the composite. It is also notable from the figure that the elastic modulus and axial strain corresponding to the compressive strength of the cement mortars increased with an increase in the GO content up to $0.1 \%$. The elastic modulus and axial strain corresponding to compressive strength enhancements of the mix containing $0.1 \%$ GO reached $109.6 \%$ and $41.9 \%$, respectively. These increases are attributed to the well-known relationship between the compressive strength, elastic modulus, and axial strain corresponding to the compressive strength.

\section{Conclusions}

In this work, the influence of GO concentration on physicochemical and mechanical properties of GO-cement mortar composites and how and why different GO concentrations affect these properties have been investigated. The results showed that the optimal percentage (i.e. $0.1 \%$ ) of GO in the composite leads to a $37.5 \%$ and $77.7 \%$ increase in the 28 days tensile and compressive strengths of GO-cement mortar composites compared to the plain cement mortar composite. Study revealed that GO not only prevents the crack propagation from the nanoscale to microscale and increases the hydration degree of the cement mortar composites, but also improves accessibility of the water to the GO oxygen functional groups and cement $\mathrm{C}-\mathrm{S}-\mathrm{H}$ component, indicating the importance of having appropriate GO concentrations. We also discovered that there is a critical GO concentration (i.e. $0.1 \%$ ) and increasing the amount of GO above this concentration leads to detrimental effects as observed by many micro-cracks related to restacking and aggregation of GO sheets in cement matrix. These observations with obtained mechanical properties that were validated by SEM, TGA, XRD, and FTIR analyses provide an essential link between structural, chemical, and mechanical properties and help to better understand the influence of GO parameters. The positive influence of GO, as a promising additive for use as a nano reinforcement, and different oxygen functional groups on the phase composition and intermolecular interaction of cementitious materials to help early-age hydration characteristics of the composite is clearly demonstrated in this work. Further investigations on the effect of other GO parameters including particle size and surface chemistry on the properties of cement mortar composites are currently underway and will be presented as a separate study. Considering scalable production and low cost availability of GO, there is strong expectation for this material to be commercially applied for the development of a new generation of cementitious and construction materials with advanced performance for broad applications. 


\section{Conflicts of interest}

There are no conflicts to declare.

\section{Acknowledgements}

The authors gratefully acknowledge the support of the Australian Research Council through ARC IH 150100003 (ARC Research Hub for Graphene Enabled Industry Transformation). The authors also thank Schools of Chemical Engineering and Civil, Environmental and Mining Engineering at the University of Adelaide for supporting this work.

\section{Notes and references}

1 C. Soranakom and B. Mobasher, Cem. Concr. Compos., 2008, 30(6), 465-477.

2 S. H. Park, D. J. Kim, G. S. Ryu and K. T. Koh, Cem. Concr. Compos., 2012, 34(2), 172-184.

3 S. Chuah, Z. Pan, J. G. Sanjayan, C. M. Wang and W. H. Duan, Constr. Build. Mater., 2014, 73, 113-124.

4 Z. Wu, C. Shi and K. H. Khayat, Cem. Concr. Compos., 2016, 71, 97-109.

5 S. Lv, Y. Ma, C. Qiu, T. Sun, J. Liu and Q. Zhou, Constr. Build. Mater., 2013, 49, 121-127.

6 Z. Pan, L. He, L. Qiu, A. Habibnejad Korayem, G. Li, J. W. Zhu, F. Collins, D. Li, W. H. Duan and M. C. Wang, Cem. Concr. Compos., 2015, 58, 140-147.

7 T. P. Chang, J. Y. Shih, K. Yang and T. C. Hsiao, J. Mater. Sci., 2007, 42(17), 7478-7487.

8 H. Madani, A. Bagheri and T. Parhizkar, Cem. Concr. Res., 2012, 42(12), 1563-1570.

9 A. K. Geim and K. S. Novoselov, The rise of graphene, Nat. Mater., 2007, 6(3), 183-191.

10 A. P. Singh, M. Mishra, A. Chandra and S. K. Dhawan, Nanotechnology, 2011, 22(46), 465701.

11 N. Ranjbar, M. Mehrali, M. Mehrali, U. J. Alengaram and M. Z. Jumaat, Cem. Concr. Res., 2015, 76, 222-231.

12 S. H. Lv, L. J. Deng, W. Q. Yang, Q. F. Zhou and Y. Y. Cui, Cem. Concr. Compos., 2016, 66, 1-9.

13 C. Lee, X. Wei, J. W. Kysar and J. Hone, Science, 2008, 321(5887), 385-388.

14 H. Y. Chu, J. Y. Jiang, W. Sun and M. Zhang, Cem. Concr. Compos., 2017, 82, 252-264.

15 T. N. Lambert, C. A. Chavez, B. Hernandez-Sanchez, P. Lu, N. S. Bell, A. Ambrosini, T. Friedman, T. J. Boyle, D. R. Wheeler and D. L. Huber, J. Phys. Chem. C, 2009, 113(46), 19812-19823.

16 H. Alkhateb, A. Al-Ostsaz, A. Cheng and X. Li, J. Nanomech. Micromech., 2013, 3(3), 67-77.

17 B. Fakhim, A. Hassani, A. Rashidi and P. Ghodousi, Sci. World J., 2014, 1-10.

18 S. Sharma and N. C. Kothiyal, RSC Adv. , 2015, 5, 52642-52657.

19 K. Gong, Z. Pan, A. H. Korayem, L. Qiu, D. Li, F. Collins, C. M. Wang and W. H. Duan, J. Mater. Civ. Eng., 2014, 27, A4014010.

20 M. L. Cao, H. X. Zhang and C. Zhang, J. Cent. South Univ., 2016, 23, 919-925.
21 C. Lu, Z. Lu, Z. Li and C. K. Y. Leung, Constr. Build. Mater., 2016, 120, 457-464.

22 D. C. Marcano, D. V. Kosynkin, J. M. Berlin, A. Sinitskii, Z. Sun, A. Slesarev, L. B. Alemany, W. Lu and J. M. Tour, ACS Nano, 2010, 4, 4806-4814.

23 ASTM C1437, Standard test method for flow of hydraulic cement mortar, ASTM International, PA, USA, 2015.

24 ASTM C307-03, Standard test method for tensile strength of chemical-resistant mortar, grouts, and monolithic surfacings, ASTM International, 2012.

25 ASTM C109/C109M-16a, Standard test method for compressive strength of hydraulic cement mortars, ASTM International, USA, 2008.

26 P. Mounanga, A. Khelidj, A. Loukili and V. Baroghel-Bouny, Cem. Concr. Res., 2004, 34, 255-265.

27 B. Lothenbach, G. L. Saout, E. Gallucci and K. Scrivener, Cem. Concr. Res., 2008, 38, 848-860.

28 B. Z. Dilnesa, E. Wieland, B. Lothenbach, R. Dahn and K. L. Scrivener, Cem. Concr. Res., 2014, 58, 45-55.

29 K. Scrivener, R. Snellings and B. Lothenbach, A Practical Guide to Microstructural Analysis of Cementitious Materials, CRC Press, 2016, ISBN: 9781138747234.

$30 \mathrm{~W}$. Czernin, Cementkemi för Byggare, Svesnka Cement Föreningen, 1959.

31 D. N. H. Tran, S. Kabiri and D. Losic, Carbon, 2014, 76, 193-202.

32 M. J. Nine, M. A. Cole, L. Johnson, D. N. H. Tran and D. Losic, ACS Appl. Mater. Interfaces, 2015, 7, 28482-28493.

33 S. Kabiri, D. N. H. Tran, S. Azari and D. Losic, ACS Appl. Mater. Interfaces, 2015, 7, 11815-11823.

34 S. Kabiri, D. N. H. Tran, M. A. Cole and D. Losic, Environ. Sci.: Water Res. Technol., 2016, 2, 390-402.

35 A. Sedaghat, M. K. Ram, A. Zayed, R. Kamal and N. Shanahan, Open J. Compos. Mater., 2014, 4(1), 12-21.

36 L. Nicoleau, T. Gadt, L. Chitu, G. Maier and O. Paris, Soft Matter, 2013, 9, 4864-4874.

37 F. Raupp-Pereira, D. Hotza, A. M. Segadaes and J. A. Labrincha, Ceram. Int., 2006, 32, 173-179.

38 N. U. Amin, S. Alam and S. Gul, RSC Adv. , 2015, 5, 6079-6084.

39 R. Wang, L. Yao and P. Wang, Constr. Build. Mater., 2013, 41, 538-544.

40 R. Alizadeh, L. Raki, J. M. Makar, J. J. Beaudoin and I. Moudrakovski, J. Mater. Chem., 2009, 19, 7937-7946.

$41 \mathrm{~N}$. Yang and W. Yue, Handbook of a collection of illustrative plates of inorganic nonmetal materials, Wuhan University of Technology Publishing Company, Wuhan, 2000.

42 E. Tkaczewska, Open J. Civ. Eng., 2013, 3(2a), 54-68.

43 A. Buchsteiner, A. Lerf and J. Pieper, J. Phys. Chem. B, 2006, 110, 22328-22338.

44 A. Mourhly, M. Khachani, A. El Hamidi, M. Kacimi, M. Halim and S. Arsalane, Nanomater. Nanotechnol., 2015, 5(35), 1-7.

45 A. Bera, T. Kumar, K. Ojha and A. Mandal, Appl. Surf. Sci., 2013, 284, 87-99.

46 G. Y. Li, P. M. Wang and X. Zhao, Carbon, 2005, 43, 1239-1245. 47 S. Cerveny, F. Barroso-Bujans, Á. Alegria and J. Colmenero, J. Phys. Chem. C, 2010, 114, 2604-2612.

48 H. Du and S. D. Pang, Cem. Concr. Res., 2015, 76, 10-19. 